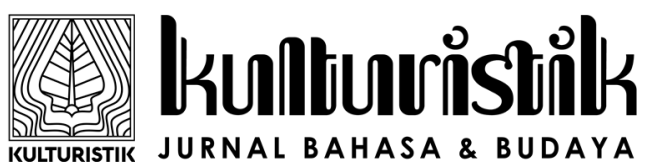

Vol. 2, No. 2, Juli 2018, 110-117

Available Online at https://ejournal.warmadewa.ac.id/index.php/kulturistik DOI: dx.doi.org/10.22225/kulturistik.2.2.717

\title{
SISTEM KEPERCAYAAN MASYARAKAT DI DAERAH ALIRAN SUNGAI (DAS) UNDA KABUPATEN KLUNGKUNG
}

\author{
Ida Bagus Astika Pidada \\ Universitas Warmadewa \\ astikapidada@gmail.com \\ I Nyoman Djuana \\ Universitas Warmadewa \\ nyomannuratni@gmail.com \\ Ni Made Suwendri \\ Universitas Warmadewa \\ suwendri63@gmail.com
}

\begin{abstract}
ABSTRAK
Daerah Aliran Sungai (DAS) Unda terletak di Kabupaten Klungkung. DAS Unda bersumber 7 buah sungai: (1) Sungai Bajing, (2) Sungai Barak, (3) Sungai Krekuk, (4) Sungai Mangening, (5) Sungai Masin, (6) Sungai Sah, dan (7) Sungai Telagawaja. Panjang sungai 24.400 meter, lebar 77 meter, kedalaman 80 sampai 1 meter, ketinggian 75 meter dengan debit air 5.422 liter/detik sampai 7.390 liter/detik. Batas hulu Sungai Unda yakni Sungai Telagawaja, termasuk Desa Selat, Kecamatan Klungkung, sedangkan bagian hilir sungai ini berakhir di Banjar Karangdadi dan Banjar Pasurungan, Desa Kusamba, Kecamatan Dawan, dimana selanjutnya bermuara ke laut ke Selat Badung. Sungai ini hampir tidak pernah kering sepanjang tahun. Masyarakat di sungai ini masih memiliki sistem kepercayaa untuk kegiatan kebudayaan, salah satu unsur kebudayaan yakni sistem relegi yakni masih digunakan sungai ini untuk tempat mandi (pesiraman) para dewa (betara). Selain itu masyarakat masih menggunakan sunggai ini untuk pembersihan diri, penghanyutan sajen kurban, penghanyutan abu jenazah, dan upacara kesuburan dan keselamatan. Tempat ini masih dipercaya masyarakat sebagai tempat yang keramat karena dihuni oleh mahkluk halus seperti: memedi, tonya, wang samar / gamang.
\end{abstract}

Kata kunci: kepercayaan, masyarakat, DAS

\begin{abstract}
[Title: The System of Community Trust in the Unda Watershed Klungkung Regency] The Unda River watershed (DAS) is located in Klungkung Regency. The Unda watershed is derived from 7 rivers: (1) Bajing River, (2) Barak River, (3) Krekuk River, (4) Mangening River, (5) Masin River, (6) Sah River, and (7) Telagawaja River. The length of the river is 24,400 meters, 77 meters wide, 80 to 1 meter deep, 75 meters in height with 5.422 liter / second up to 7,390 liter / sec of water flow. The upper limit of the Unda River is Telagawaja River, including the Selat Village, Klungkung District, while the downstream of this river ends in Banjar Karangdadi and Banjar Pasurungan, Kusamba Village, Dawan Subdistrict, which further extends into the sea to the Badung Strait. The river is almost never dry throughout the year. Communities in this river still have a system of trust for cultural activities, one of the cultural elements of the religious system that is still used this river for the bath (pesiraman) the gods (betara). In addition, people still use this river for self-cleaning, sacrificial sacrifice, ashes, and fertility and safety ceremonies.
\end{abstract}


Vol. 2, No. 2, Juli 2018, 111

Available Online at https://ejournal.warmadewa.ac.id/index.php/kulturistik DOI: dx.doi.org/10.22225/kulturistik.2.2.717

This place is still trusted by the community as a sacred place because it is inhabited by such subtle creatures: memedi, tonya, wang samar / gamang.

Keywords: trust, society, watershed

\section{PENDAHULUAN}

Setiap manusia sadar selain dunia yang fana ini, ada suatu alam dunia yang tidak tampak olehnya, dan berada di luar batas akalnya. Dunia itu adalah dunia alam gaib. Berbagai kebudayaan menganut kepercayaan bahwa dunia gaib dihuni berbagai makhluk dan kekuatan yang tidak dapat dikuasai manusia dengan cara biasa, karena itu dunia gaib ditakuti oleh manusia (Koentjaraningrat, 1998: 203).

Manusia sebenarnya makhluk lemah, penakut dan cenderung membutuhkan sesuatu lebih kuat dari dirinya. Dari sini muncullah keyakinan - keyakinan atau kepercayaan sesuatu yang dianggap misterius diyakini jauh lebih kuat dan hebat dari manusia. Untuk mewujudkan keyakinan dan ketundukkan manusia tersebut, timbullah kegiatan/upacara berbentuk pemujaaan dan ibadat. Semua ibadat dilakukan manusia dalam bentuk beragam sesuai kepercayaannya.

Dengan demikian kepercayaan mempunyai arti adanya suatu anggapan (keyakinan) atau kepercayaan bahwa benar - benar ada atau sesuatu yang dipercaya keberadaannya baik itu berupa dewa - dewa dan orang halus hingga sekarang (Poerwadarminta, 1976: 737 - 955).

Agama muncul berawal dari kepercayaan terhadap sesuatu yang dianggap suci dan sakral. Kepercayaan tersebut terorganisasi dengan munculnya agama. Demikian halnya sistem kepercayaan masyarakat yang penulis teliti di daerah aliran sungai (DAS) Unda Kabupaten Klungkung. DAS diartikan pengumpul air bagi sungai induk beserta anak - anak sungai yang meliputi satu sistem (Anonim, n.d. : 213). Unda berarti pindahkan dengan cara sambung menyambung (Warna, 1978: 605 - 626). Sungai Unda diartikan air sungai yang dipindahkan dengan cara sambung menyambung. DAS Unda bersumber dari banyak sungai, karena itu tidak pernah mengalami kekeringan.

Masyarakat di DAS Unda menggunakan sungai ini, baik dari hulu sampai ke hilir dipercaya untuk kegiatan kebudayaan. Salah satu unsur kebudayaan, yakni sistem religi yaitu tradisi mesiram (mandi) betara (dewa) berlangsung hingga sekarang. Sistem kepercayaan lain yang ditemukan di DAS Unda yaitu upacara kesuburan dan keselamatan untuk pertanian, pembersihan diri, menghanyutkan abu jenasah serta menghanyutkan sajen kurban. Masyarakat di DAS Unda masih percaya bahwa dipinggir sungai dianggap sebagai tempat yang keramat, karena dihuni oleh makhluk halus seperti: memedi, tonya, wang samar/ gamang. Oleh sebab itu masyarakat tidak berani merusak/ mengganggu lingkungan di pinggiran sungai tersebut bahkan mereka berusaha menjaga kebersihan dan memelihara lingkungan serta tidak mengizinkan menebang pepohonan sembarangan supaya lingkungan tetap lestari.

\section{METODE}

Sistem Kepercayaan Masyarakat di DAS Unda mengambil lokasi penelitian di Kabupaten Klungkung. Batas hulu Sungai Unda yakni Sungai Telagawaja, Sedangkan batas hilir Sungai Unda di Desa Kusamba.

Sumber data dalam penelitian ini terdiri data primer dan data sekunder. 
Vol. 2, No. 2, Juli 2018, 112

Available Online at https://ejournal.warmadewa.ac.id/index.php/kulturistik DOI: dx.doi.org/10.22225/kulturistik.2.2.717

Data primer diperoleh di lapangan dengan melakukan observasi dan wawancara kepada informan secara mendalam dilakukan sepanjang dilalui aliran Sungai Unda.Informan yang diwawancarai adalah orang yang mengetahui keberadaan sungai tersebut. Selanjutnya data sekunder diperoleh dari beberapa penulis tentang sungai tersebut yang dilengkapi dengan dokumentasi berupa kamera.

Data yang berhasil dikumpulkan selanjutnya diolah dan diklasifikasikan dengan membuang yang tidak perlu.Model analisis data yang diterapkan dalam penelitian ini bersifat deskriptif kualitatif.Analisa data dilakukan mulai dari pengumpulan data. Analisa data dilakukan dalam hal ini secara terus menerus mulai dari awal maupun selama proses penelitian berlangsung. Dalam hal ini pertanyaan diperdalam serta dikembangkan crosscheck untuk verifikasi.

Metode yang dipakai dalam penyajian hasil penelitian ini adalah metode informal. Metode informal dalam hal in adalah penyajian hasil analisis dengan untaian kata - kata agar penjelasannya terurai dan terinci (Sudaryanto, 1986: 45)

\section{PEMBAHASAN}

\section{Sistem Kepercayaan Masyarakat Di DAS Unda Kabupaten Klungkung \\ 1. Permandian Para Dewa}

Dalam menghubungkan diri dengan Ida Sang Hyang Widhi Wasa/ Tuhan Yang Mahaesa, umat Hindu mempunyai tempat suci untuk beribadah, yakni disebut pura, sanggah/pemerajan. Pura menurut fungsinya ada 2 jenis, yaitu pura umum sebagai pemujaan Hyang Widhi dengan manifestasi-Nya dan pura pemujaan roh suci leluhur sesuatu keluarga. Pura yang disebut belakangan ini bersifat geneologis. Pura umum mempunyai tingkatan menurut kesatuan teritorial, yakni tingkat daerah, tingkat kabupaten, tingkat kecamatan dan tingkat desa adat. Demikian pula, pura leluhur mempunyai tingkatan berdasarkan susunan geneologis sesuatu klen/warga. Tingkat terendah adalah sanggah/pemerajan sedangkan tingkatan di atasnya adalah pratiwi, ibu, panti, dadya, dan terakhir adalah padharman yang terletak di kelompok Pura Besakih di kaki Gunung Agung (Ardana et al., 1983/1984).

Pertemuan 2 atau 3 sungai dipandang sebagai tempat suci, baik di India maupun di Bali (Titib, 2001: 78 - 86). Masyarakat di DAS Unda menyebutnya penyampuhan, berasal dari kata sapuh berarti bersih. Penyampuhan diidentikkan dengan pembersihan. Penyampuhan di hulu DAS Unda yaitu pertemuan Sungai Telagawaja dengan Sungai Masin dan Sungai Unda. Apabila ada piodalan (perayaan ulang tahun) di Pura Desa Betara (Dewa) di Desa Apet, seperti: Betara di Pura Dalem, di Pura Puseh, di Pura Desa serta Betara pada Pura - Pura Paibon (Pura tempat pemujaan leluhur dari keluarga yang masih jelas pertalian kekerabatan) datang ke penyampuhan untuk mesiram (mandi), sebelum upacara piodalan di mulai. Betara yang mandi dilengkapi banten pakelem (sajen upacaraditenggelamkan) memakai bebek selem (itik hitam) dipimpin Jero Mangku Desa/pemuka agama di desa (Hasil wawancara dengan I Made Dana, 2 Juni 2017).

Penyampuhan juga ditemukan di hilir DAS Unda, di Pura Seganing yang merupakan pertemuan Sungai Bayung dengan Sungai Unda. Sebelum puja wali (upacara Dewa Yadnya) di Pura Panti Timbrah Paksebali Klungkung dimulai, Betara (Dewa) di pura ini mesiram (mandi) terlebih dahulu ke Pura Taman Seganing yaitu ke penyampuhan pada hari raya Kuningan (Hasil wawancara dengan I Wayan Sudana, 21 Juni 2017). Di penyampuhan ini ada 2 pura, yakni di bawah bernama Pura Taman dan di atas bernama Pura Seganing. Kedua pura ini 
Vol. 2, No. 2, Juli 2018, 113

Available Online at https://ejournal.warmadewa.ac.id/index.php/kulturistik DOI: dx.doi.org/10.22225/kulturistik.2.2.717

umumnya disebut Pura Seganing. Setelah selesai mesiram (mandi) Betara (Dewa) ini mesolah (menari) kemudian baru keaturan pujawali (dipersembahkan upacara kepada para Dewa). Piodalan di Pura Panti Timbrah Paksebali setiap 6 bulan sekali yakni pada hari raya Kuningan dimana nyejer (bersemayam) selama 11 hari. Pada waktu piodalan disuguhkan tarian rejang dan tarian lente. Di Pura Panti Timbrah Paksebali ada 7 buah joli (jempana/singga sanayang ditandu tanpa sandaran), yakni 1 joli dari Bugbug dan 6 joli dari Timbrah Klungkung. Betara (Dewa) Ratu Lingsir mekampuh (raja tua berselimut) puth 1 buah, mekampuh gringsing poleng (loreng) 1 buah, dan sisanya 5 buah mekampuh buduk prasok (sejenis alang - alang) (Hasil wawancara dengan Made Mustika, 7 Juni 2017).

\section{Penghanyutan Sajen Kurban (Banten caru)}

Salah satu upacara lain yang terkait dengan sistem relegi dan merupakan bagian dari unsur kebudayaan di DAS Unda Kabupaten Klungkung adalah upacara mecaru (upacara kurban). Masyarakat di DAS Unda apabila melakukan upacara mecaru (upacara kurban), banten (sajen) tersebut biasanya dihanyutkan ke Sungai Unda. Banten caru biasanya dihanyutkan masyarakat setelah selesai melakukan upacara, yakni pada siang hari sekitar pukul 11.00 WITA atau sore hari yaitu sekitar pukul 17.00 WITA (Hasil wawancara dengan Ida Bagus Putu Wijaya, 14 Juni 2017). Tempat menghanyutkan banten caru oleh masyarakat dicari air yang deras dan dekat dengan Sungai Unda. Menghanyutkan banten caru (sajen kurban) tidak lain bertujuan membuang mala (kotor atau noda). Pada waktu membuang banten caru, menggunakan sarana banten pemeralina (sajen pelebur) (Hasil wawancara dengan Ida Bagus Ngurah, 14 Juni 2017).

\section{Penghanyutan Abu Jenazah}

Abu jenazah yang telah diupacarai dihanyutkan ke Sungai Unda pada alur sungai yang deras dan lokasinya sudah ditentukan. Abu jenazah dibawa menggunakan jempana (usungan untuk memikul lambang dewa - dewa) dan ada menggunakan bokor (talam kecil terbuat dari perak yang diukir). Abu jenazah yang dihanyutkan masyarakat, baik berada di sebelah timur maupun di sebelah barat Sungai Unda, posisinya terletak di sebelah selatan jembatan lama/di sebelah utara jembatan baru. Sebelum menghanyutkan abu jenazah terlebih dahulu menghaturkan banten penganyutan. Abu jenazah yang dihanyutkan umumnya dilakukan lewat pukul $13.00 \mathrm{WITA} /$ sore hari (Hasil wawancara dengan Ida Bagus Arnawa, 25 September 2017).

Masyarakat di hulu DAS Unda seperti dari Desa Apet, Desa Tegak, Desa Selat, dan Desa Cucukan menghanyutkan abu jenazah ke Sungai Telagawaja. Ada yang menghanyutkan dari jembatan dan ada dari bawah jembatan dengan terlebih dahulu menghaturkan banten penghanyutan (Hasil wawancara dengan Ida Bagus Werdika, 25 September 2017). Sedangkan seluruh banjar adat Klungkung kota yang berada pada posisi di tengah - tengah menghanyutkan abu jenazah di DAS Unda seperti : dari Semarapura Kangin (Timur), Semarapura Kelod (Selatan), Semarapura Kauh (Barat), Semarapura Tengah, Semarapura Kaja (Utara), dan Desa Akah. Selanjutnya masyarakat yang menghanyutkan abu jenazah di sebelah timur DAS Unda seperti dari Desa Adat Sulang dan Desa Adat Sampalan. Desa Adat Sampalan mewilayahi 3 (tiga) Desa Dinas, yakni: Paksebali, Sampalan Tengah, dan Sampalan Kelod. Masyarakat Desa Paksebali dan Sulang menghanyutkan abu jenazah di sebelah Selatan jembatan lama/di sebelah utara jembatan baru 
Vol. 2, No. 2, Juli 2018, 114

Available Online at https://ejournal.warmadewa.ac.id/index.php/kulturistik DOI: dx.doi.org/10.22225/kulturistik.2.2.717

jurusan Karangasem - Klungkung. Akan tetapi, masyarakat Sampalan Tengah dan Sampalan Kelod tempat menghanyutkan abu jenazahnya di daerah Pijig, yakni perbatasan Desa Tangkas dan Desa Kacangdawa. Tradisi menghanyutkan abu jenazah ke Sungai Unda sudah berlangsung dari dulu sampai sekarang.

\section{Pembersihan Diri}

Masyarakat yang datang ke tempat pertemuan sungai tidak saja untuk kegiatan permandian para dewa juga pembersihan diri. Di hilir DAS Unda pertemuan sungai di temukan Sungai Bayung dengan Sungai Unda. Sedangkan di hulu DAS Unda tempat pertemuan sungai ditemukan Sungai Telagawaja, Sungai Masin dan Sungai Unda. Demikian pertemuan Sungai Telagawaja, Sungai Masin dan Sungai Unda dianggap suci oleh masyarakat sekitar sungai tersebut. Masyarakat sekitar sungai ini menyebutnya dengan nama penyampuhan, berasal dari kata $s a p u h=$ bersih. Banyak orang datang ke penyampuhan melakukan pembersihan diri (melukat) karena mereka mempunyai perasaan kotor/kurang bersih seperti : dari Desa Pegending, Pesaban, Tegak, Bajing, Tulangnyuh, dan Desa Bakas. Mereka secara pribadi melakukan pembersihan diri dengan terlebih dahulu menghaturkan banten pejati (sajen permakluman bahwa akan dilangsungkan suatu upacara) (Warna, $1978: 245$ ).

\section{Kesuburan Dan Keselamatan}

Salah satu upacara yang berkaitan dengan pertanian, yakni upacara kesuburan dan keselamatan berupa pemotongan kerbau, seperti yang dilakukan oleh Subak Payungan, Bajing, Akah, dan Besang yang menggunakan waduk/ bendungan Buke di desa Payungan sebagai sumber air pertaniannya. Subak di atas secara bergilir setiap1 tahun sekali menyelenggarakan yaitu tepatnya purnama keenam (purnama ke enam). Dana pemotongan kerbau diperoleh dari warga subak. Setiap warga subak dikenakan uang sebesar Rp 500,00/per are, tergantung dari luas sawah yang dimilikinya (Hasil wawancara dengan I Made Dana, 2 Juni 2017). Apabila tidak melakukan pemotongan kerbau, maka waduk/ bendungan yang dimiliki warga subak di atas selalu bocor. Mereka tidak berani memotong hewan lain selain kerbau. Kerbau yang digunakan untuk upacara kurban (mecaru) adalah anak kerbau (godel). Sajen upacara pemotongan kerbau bernama banten pemakpag toya (sajen mendatangkan air). Petugas yang menyelesaikan (muput) pemotongan kerbau adalah pendeta (pedanda) dari Geria Bajing Klungkung. Sebelum dilukai kerbau tersebut dihias terlebih dahulu kemudian diarak keliling Pura Puseh beberapa kali yang diiringi gamelan bleganjur. Dari sini kerbau dilanjutkan perjalanannya menuju terowongan (aungan) lepas tewel. Kerbau mulai dilukai kakinya dari terowongan lepas tewel yang berlokasi di Desa Payungan. Kerbau yang kakinya sudah mengeluarkan darah, kemudian dituntun oleh warga subak. Darah yang keluar bercampur dengan air sungai mengalir ke sawah - sawah subak di atas. Warga subak berharap sawah yang dimilikinya memperoleh kesuburan dan hasilnya berlimpah. Kerbau yang sudah dilukai ini, berakhir perjalanannya di Pura Dalem Suci Payungan dan selanjutnya dipotong. Dagingnya dibagikan kepada warga subak.Pemotongan kerbau selesai siang hari.

\section{Daerah Keramat}

Menurut kepercacayaan masyarakat Hindu di Bali di pinggiran sungai, 
Vol. 2, No. 2, Juli 2018, 115

Available Online at https://ejournal.warmadewa.ac.id/index.php/kulturistik

DOI: dx.doi.org/10.22225/kulturistik.2.2.717

gunung, dan hutan dianggap tempat yang keramat. Tempat - tempat ini dihuni oleh memedi (orang halus yang suka menyembunyikan anak kecil), tonya (nama makhluk halus, hantu), wang samar atau gamang (orang halus), atau sejenis jin (Warna, 1978: 184 - 600; Poerwadarminta, 1976 : 419) . Demikian DAS Unda Kabupaten Klungkung masyarakat sampai sekarang masih percaya dipinggiran sungai ini di dihuni oleh makhluk halus seperti: memedi, tonya, wang samar/ gamang. Beberapa gangguan yang pernah dialami oleh masyarakat seperti: Ida Bagus Wijaya pada waktu mencari jangkrik di Tibu Cenana pernah melihat orang besar (Hasil wawancara dengan Ida Bagus Putu Wijaya, 14 Juni 2017). Masyarakat sering melihat wanita cantik yang punggungnya berlubang (rek-rek tunggek) di Tukad Bolong anak sungai dari Sungai Unda. Di daerah Sapi dipinggir Sungai Unda pernah masyarakat melihat ular tanpa ekor (Hasil wawancara dengan Ida Bagus Putra, 25 September 2017). Di DAS Unda masyarakat pernah melihat penampakan basang - basang (isi perut) (Hasil wawancara dengan Ida Bagus Arnawa, 25 September 2017). Penampakan pernah dilihat oleh Ida Bagus Ardika ketika memancing ikan di Pura Ulun Titi jembatan lama berupa anjing hitam sebesar sapi (Hasil wawancara dengan Ida Bagus Ardika, 14 Juli 2017). Anak Agung Raka pernah tinggal di sebelah selatan jembatan lama, pada waktu itu terjadi hujan lebat. Tiba - tiba mendengar suara supaya pergi dari rumah itu, ternyata tebing di sebelah timur longsor menimbun rumahnya (Hasil wawancara dengan Anak Agung Raka, 10 Juni 2017). Pernah ada seorang pedagang dari Desa Satria ketika pulang dari berdagang malam hari bertemu seorang gadis cantik bernama Ida Ayu Ngurah untuk mampir di rumahnya bertemu dengan ayahnya seorang pendeta (Hasil wawancara dengan Ida Bagus Pidada Kaut, 25 Juni 2017). Adanya penampakan dan gangguan tersebut rakyat di daerah aliran Sungai Unda menambah kepercayaan bahwa di pinggir sungai ini masih dihuni oleh makhluk - makhluk halus. Di tempat ini di bangun tempat suci oleh masyarakat dengan nama Pura Ulun Titi.Adapun tujuannya agar diberi keselamatan serta tidak diganggu oleh orang - orang halus. Masyarakat juga menjaga kebersihan dan memelihara lingkungan serta tidak mengizinkan menebang pepohonan sembarangan supaya lingkungan tetap lestari. Hal ini sesuai dengan kepercayaan rakyat Bali bahwa orang dilarang merabas pohon - pohonan tanpa tujuan yang mulia (Ardana \& $\mathrm{Al}$, n.d. : 68).

\section{Makna Sistem Kepercayaan Yang Dimiliki Masyarakat Di Daerah Aliran Sungai (DAS) Unda Kabupaten Klungkung}

Pegunungan yang membujur dari barat ke timur Pulau Bali umumnya membentuk beberapa sungai. Berkaitan sungai sebagai sumber mata air, masyarakat Hindu di Bali memiliki konsep dalam memelihara lingkungannya. Konsep tersebut disebut dengan Sad Kerti terdiri atas Danu Kerti, Atma Kerti, Samudra Kerti, Jagad Kerti, Jana Kerti, Wang Kerti(Wiana, 1998: 23). Satu diantara Sad Kerti adalah Danu Kerti, bertujuan untuk memahami fungsi sumber air, seperti: telaga, mata air, danau, sungai. Danu Kerti mengajarkan kita baik dalam kebersamaan maupun kesendirian melindungi sumber air demi kelangsungan hidup makhluk lain.

Pertemuan 2 atau 3 sungai dipandang sebagai tempat suci baik di India maupun di Bali (Titib, 2001: 78 - 86). Air adalah sarana untuk mendapatkan air suci. Hal ini sesuai dengan pendapat Puja dan Sudarta. Masyarakat dilarang kencing, meludah, mengucapkan perkataan yang tidak suci, dan mengeluarkan darah/ 
Vol. 2, No. 2, Juli 2018, 116

Available Online at https://ejournal.warmadewa.ac.id/index.php/kulturistik

DOI: dx.doi.org/10.22225/kulturistik.2.2.717

hal - hal yang berbisa serta kotoran lainnya ke dalam sungai maupun sumber mata air lainnya. Hal ini kutukannya sangat berat bagi yang melakukan, harus membuat upacara Mulang Pakelem ke sungai atau danau (Puja \& Sudarta, 1996: 224 602).

Demikian DAS Unda Kabupaten Klungkung ada pertemuan beberapa sungai yang dianggap suci disebut penyampuhan. Di hulu pertemuan sungai seperti: Sungai Telagawaja dengan Sungai Masin dan Sungai Unda. Sedangkan di hilir pertemuan seperti: Sungai Bayung dan Sungai Unda. Pertemuan sungai sungai di atas sesuai dengan konsep agama Hindu dianggap suci sehingga digunakan untuk kegiatan religius seperti memperoleh air suci, permandian para dewa, pembersihan diri. DAS Unda juga digunakan oleh masyarakat untuk mencari air teben - dulu (hilir - hulu) untuk upacara ngaben, penghanyutan abu jenazah serta penghanyutan sajen kurban. Sehubungan pentingnya arti sungai sungai di atas untuk kegiatan upacara agama, masyarakat berusaha menjaga kesucian air sungai ini. Apapun kegiatan agama dilakukan oleh masyarakat di sungai ini, terlebih dahulu menghaturkan sajen (banten) agar mereka memperoleh keselamatan. Apalagi ada kepercayaan masyarakat agama Hindu di Bali bahwa di pinggiran sungai, gunung, dan hutan dianggap sebagai tempat yang keramat. Tempat ini sering dihuni oleh memedi (orang halus yang suka menyembunyikan anak kecil), tonya (nama makhluk halus, hantu), wang samar atau gamang (orang halus) atau sejenis jin (Warna, 1978: 184 - 600; Poerwadarminta, 1976: 419). Berbagai jenis penampakan pernah dilihat oleh masyarakat di DAS Unda sehingga menambah keyakinan mereka bahwa dipinggiran sungai ini ada makhluk makhluk halus menghuninya. Masyarakat tidak berani mengganggu lingkungan dipinggiran sungai tersebut mereka berusaha menjaga kelestarian lingkungannya.

\section{SIMPULAN}

Daerah aliran Sungai Unda merupakan sungai terpanjang untuk Bali Timur. Masyarakat DAS Unda menyebutnya sungai ini Yeh Unda/Tukad Un$d a$.Berkaitan dengan sungai sebagai sumber mata air, masyarakat Agama Hindu di Bali memiliki konsep dalam memelihara lingkungannya. Konsep yang dimaksud disebut Sad Kerti, Salah satu diantaranya Danu Kerti bertujuan untuk memahami fungsi sumber air, seperti: telaga, mata air, danau, sungai. Danu Kerti mengajarkan manusia baik dalam kebersamaan maupun kesendirian berusaha melindungi sumber air demi kelangsungan hidup makhluk lain.Masyarakat dilarang kencing, meludah, mengucapkan perkataan tidak suci, dan mengeluarkan darah/ hal - hal yang berbisa serta kotoran lainnya, baik ke dalam sungai maupun sumber mata air lainnya. Dalam hal ini kutukannya sangat berat bagi yang melakukan harus membuat upacara Mulang Pakelem ke sungai/danau. Pertemuan 2 atau 3 sungai dipandang sebagai tempat suci baik di India maupun di Bali. Demikian halnya DAS Unda, di hulu sungai ada pertemuan sungai yang dianggap suci disebut penyampuhan yaitu Sungai Telagawaja, Sungai Masin, dan Sungai Unda. Sedangkan di hilir, pertemuan Sungai Bayung dengan Sungai Unda. Pertemuan sungai - sungai di atas digunakan kegiatan keagamaan seperti memperoleh air suci, permandian para dewa, pembersihan diri, mencari air hilir - hulu untuk upacara ngaben, penghanyutan abu jenazah, penghanyutan sajen kurban serta untuk kesuburan dan keselamatan pertanian. Masyarakat agama Hindu di Bali percaya bahwa di pinggiran sungai, gunung dan hutan dianggap sebagai tempat yang keramat/tenget, karena sering dihuni oleh memedi, tonya, wang samarl 


\section{Lisulturisiolink \\ KULTURISTIK JURNAL BAHASA \& BUDAYA}

Vol. 2, No. 2, Juli 2018, 117

Available Online at https://ejournal.warmadewa.ac.id/index.php/kulturistik

DOI: dx.doi.org/10.22225/kulturistik.2.2.717

gamang. Demikian halnya DAS Unda berbagai penampakan dilihat masyarakat menambah keyakinan mereka bahwa di pinggiran sungai dihuni oleh makhluk makhluk halus sehingga tidak berani mengganggu lingkungan di pinggiran sungai tersebut, mereka berusaha menjaga kelestarian lingkungannya.

\section{DAFTAR PUSTAKA}

Anonim. (n.d.). Ensiklopedi nasional Indonesia. Jakarta: PT. Delta Pamungkas.

Ardana, I. G. G., \& Al, E. (n.d.). Pedoman penerangan agama hindu dan budha tentang agama hindu dan lingkungan hidup. Denpasar: Proyek Penerangan Bimbingan dan Dakwah / Khotbah Agama Hindu dan Budha.

Koentjaraningrat. (1998). Pengantar antropologi II. Jakarta: PT. Rineka Cipta.

Poerwadarminta, W. J. . (1976). Kamus umum bahasa Indonesia. Jakarta: PN. Balai Pustaka.

Puja, G., \& Sudarta, R. (1996). Manawa dharma sastra. Jakarta: Hanuman Sakti.

Titib, I. M. (2001). Teologi simbol-simbol dalam agama hindu. Surabaya: Paramita.

Warna, I. W. (1978). Kamus Bali Indonesia. Denpasar: Dinas Pengajaran Propinsi Daerah Tingkat I Bali.

Wiana, K. (1998). Pelestarian lingkungan hidup menurut konsep hindu. Widia Satya Dharma Jurnal Kajian Hindu, Budaya Dan Pembangunan. 